\title{
Inokulasi Mikoriza pada Media Tanam Campuran Kompos Kotoran Kambing Terhadap Pertumbuhan Bibit Kakao
}

\section{Mycorrhiza Inoculation in Mixed Growing Media of Goat Manure Compost on the Growth of Cocoa Seedlings}

\author{
Dedi Kurniawan*1), Triara Juniarsih²) dan Fitra Syawal Harahap ${ }^{3)}$ \\ 1) 2) Program Study of Agrotechnology, Faculty of Agriculture and Animal Husbandry, Universitas Tjut Nyak Dhien, Medan, Indonesia \\ ${ }^{3)}$ Department of Agrotechnology, Faculty of Sains and Technology, Universitas Labuhanbatu, Labuhanbatu, Indonesia \\ ${ }^{*}$ Corresponding author: dedijono27@gmail.com
}

Received: September 12, 2021; Accepted: September 24, 2021; Published: October 31, 2021

\begin{abstract}
Improvements in cocoa cultivation techniques need to be done by adding goat manure as a mixture of planting media to improve the physical properties of the soil in order to make it easier for roots to develop. This objective of this study was to determine concentration of mycorrhizae, the best growing media for cocoa seedlings, and interaction on the growth of cocoa seedlings. The method used was randomized block design with two factor. The first factor was the inoculation of mycorrhizae consisting of four levels: without inoculation of mycorrhizae $10 \mathrm{~g} / \mathrm{plant}, 20 \mathrm{~g} / \mathrm{plant}$, and 30 $\mathrm{g} /$ plant. The second factor was the growing media with three levels of growing media: top soil, top soil + goat manure compost (1:1), and top soil + goat manure compost (1:2). The results showed that the growing media had a significant effect on the height and volume of plant roots. Growing media of top soil produced the best average seedling by $38.06 \mathrm{~cm}$ and root volume by $4.39 \mathrm{~cm} 3$. The interaction of giving mycorrhizae with growing media had a significant effect on root volume with the best treatment $10 \mathrm{~g} /$ plant mycorrhizae and top soil by $5.67 \mathrm{~cm} 3$. The results analysis of root infection by arbuscular mycorrhizal fungi showed the highest infection in the $20 \mathrm{~g} / \mathrm{plant}$ mycorrhizae and top soil by $80 \%$. Application of mycorrhizae with growing media can increase cocoa yield and growth. Planting media mycorrhizae infected to soil can affect cocoa seedling.
\end{abstract}

Key words: organic fertilizer; root system; soil quality

Cite this as: Kurniawan, D., Juniarsih, T. \& Harahap, F. S. (2021). Inokulasi mikoriza pada media tanam campuran kompos kotoran kambing terhadap pertumbuhan bibit kakao. Agrosains : Jurnal Penelitian Agronomi, 23(2), 119-123. DOI: http://dx.doi.org/10.20961/agsjpa.v23i2.54992

\section{PENDAHULUAN}

Kakao merupakan salah satu komoditas unggulan sub sektor perkebunan. Komoditi kakao secara konsisten berperan sebagai sumber devisa negara yang memberikan kontribusi yang sangat penting dalam struktur perekonomian Indonesia (Arsyad et al., 2011). Luas areal perkebunan kakao Indonesia pada tahun 2018 mencapai 1,61 juta Ha. Pada tahun 2019 diperkirakan luas areal perkebunan kakao mengalami penurunan sebesar 1,14 persen dari tahun 2018 menjadi 1,59 juta Ha. Ekspor kakao Indonesia pada tahun 2018 mencapai 380,83 ribu ton dengan total nilai sebesar US $\$ 1,25$ milyar, turun menjadi 358,48 ribu ton pada tahun 2019 dengan total nilai sebesar US $\$ 1,20$ milyar (Sub Direktorat Statistik Tanaman Perkebunan, 2020).

Penyebab utama produktivitas kakao mengalami penurunan salah satunya disebabkan oleh pohon-pohon yang sudah tua yang menyebabkan tanaman tidak produktif (Sulistyowati, 2014). Salah satu usaha yang dapat dilakukan untuk meningkatkan kualitas maupun kuantitas produksi kakao adalah penyediaan bahan tanam dalam pembibitan karena dari pembibitan inilah akan didapatkan bahan tanam yang layak untuk ditanam di lapangan yang nantinya akan menghasilkan tanaman kakao yang mampu memproduksi hasil kakao secara maksimal (Dalimunthe et al., 2015). Pembibitan kakao berperan penting dalam menghasilkan kualitas bibit yang bermutu. Banyak upaya yang telah dilakukan untuk mendapatkan bibit yang diharapkan, seperti perbaikan media tanam dengan campuran bahan organik.

Berbagai jenis campuran media tanam dapat kita gunakan, seperti limbah ternak. Limbah ternak berpotensi sebagai sumber pupuk organik terutama pada kotoran kambing. Pupuk kotoran kambing mengandung nilai rasio $\mathrm{C} / \mathrm{N}$ sebesar $21,12 \%$ (Cahaya \& Nugroho, 2009). Selain itu, kadar hara kotoran kambing mengandung $\mathrm{N}$ sebesar $1,41 \%, \mathrm{P}$ sebesar $0,54 \%$, dan $\mathrm{K}$ sebesar $0,75 \%$ (Hartatik \& Widowati, 2006).

Pencampuran kompos kotoran kambing dalam media tanam selain diaplikasikan secara mandiri dapat juga diaplikasikan bersama dengan mikoriza. Penggunaan mikoriza pada tanaman kakao akan lebih efektif bila dilakukan pada saat pembibitan, dimana pemberian mikoriza dapat memberikan peluang lebih besar untuk mikoriza menginfeksi akar tanaman (Noertjahyani, 2012). Adapun manfaat mikoriza dalam menginfeksi akar tanaman bagi perkembangan 
tanaman yang menjadi inangnya, yaitu meningkatkan absorbsi hara dari dalam tanah, sebagai penghalang biologis terhadap infeksi patogen akar, meningkatkan ketahanan inang terhadap kekeringan, dan meningkatkan hormon pemacu tumbuh (Noli et al., 2011). Menurut Rungkat (2009) prinsip kerja mikoriza adalah menginfeksi sistem perakaran tanaman inang dan memproduksi jalinan hifa secara intensif, sehingga tanaman yang mengandung mikoriza tersebut akan mampu meningkatkan kapasitas dalam penyerapan hara. Faktor-faktor yang dapat mempengaruhi perkembangan mikoriza selain $\mathrm{pH}$ tanah, kondisi tanah yang lain yang mempengaruhi adalah drainase, ketersediaan bahan organik, dan ketersediaan hara. Mikoriza akan dapat berkembang dengan baik apabila tidak ada hambatan aerasi. Ketersediaan hara terutama nitrogen dan fosfat yang rendah akan mendorong pertumbuhan mikoriza. Sebaliknya kandungan hara yang terlalu rendah atau terlalu tinggi menghambat pertumbuhan mikoriza (Islami et al., 1995). Tujuan penelitian ini adalah untuk mengetahui pertumbuhan vegetatif bibit kakao dengan adanya inokulasi mikoriza dan kompos kotoran kambing sebagai campuran media tanam.

\section{BAHAN DAN METODE}

Penelitian dilaksanakan di lahan pertanian milik masyarakat Kelurahan Tunggurono Kecamatan Binjai Timur Kota Binjai Sumatera Utara yang dimulai pada bulan Februari-Juli 2021. Bahan-bahan yang digunakan dalam penelitian ini adalah benih kakao, kotoran kambing, mikoriza, top soil, larutan EM4, dan bahan pendukung penelitian lainnya. Alat-alat yang digunakan adalah meteran, schalifer, paranet, dan alat pendukung penelitian lainnya.

Metode yang digunakan dalam penelitian ini adalah Rancangan Acak Kelompok (RAK) Faktorial dengan 2 faktor perlakuan, yaitu: Faktor I : Mikoriza (M) yang terdiri dari 4 taraf, yaitu: $M_{0}=0 \mathrm{~g} / \tan , M_{1}=10 \mathrm{~g} / \tan , M_{2}$ $=20 \mathrm{~g} / \mathrm{tan}$, dan $\mathrm{M}_{3}=30 \mathrm{~g} / \mathrm{tan}$, Faktor II : Media Tanam ( $\mathrm{T}$ ) yang terdiri dari 3 taraf, yaitu: $\mathrm{T}_{0}=$ Top soil, $\mathrm{T}_{1}=$ Top soil + kompos kotoran kambing (1:1), dan $\mathrm{T}_{2}=$ Top soil + kompos kotoran kambing (1:2). Pelaksanaan penelitian dimulai dari pengomposan kotoran kambing dengan menyiapkan lokasi untuk pengomposan kotoran kambing yang bebas dari genangan air dan terpaan hujan, lalu menyiapkan ember yang sudah diisi dengan bakteri EM4 sesuai dosis dan menambahkan air secukupnya ke dalam ember tersebut. Selanjutnya larutan EM4 tersebut disiramkan pada kotoran kambing dan didiamkan selama \pm 4 minggu. Pengisian media tanam terdiri dari top soil serta campuran top soil dengan kompos kotoran kambing sesuai perlakuan. Sebelum melakukan penanaman, terlebih dahulu membuat lubang tanam sedalam $4 \mathrm{~cm}$ pada media tanam, kemudian diinokulasikan mikoriza ke dalam lubang tanam, benih dimasukkan dan ditutup dengan tanah. Pengamatan variabel yaitu tinggi bibit, jumlah daun dan derajat infeksi akar. Data yang diperoleh untuk mengetahui ada tidaknya pengaruh perlakuan dan adanya interaksi perlakuan, diuji dengan analisis ragam pada taraf $5 \%$. Untuk pengujian lebih lanjut menggunakan Duncan's Multiple Range Test (DMRT) pada taraf $5 \%$.

\section{HASIL DAN PEMBAHASAN \\ Tinggi Bibit}

Hasil analisis sidik ragam menunjukkan bahwa perlakuan media tanam berpengaruh nyata terhadap tinggi bibit, sedangkan perlakuan pemberian mikoriza dan interaksi pemberian mikoriza dengan media tanam tidak berpengaruh nyata terhadap tinggi bibit kakao (Tabel 1).

Tabel 1. Tinggi bibit kakao melalui inokulasi mikoriza pada media tanam campuran kompos kotoran kambing

\begin{tabular}{ccccc}
\hline \multirow{2}{*}{ Perlakuan } & \multicolumn{4}{c}{ Media Tanam } \\
\cline { 2 - 4 } & $\mathrm{T}_{0}$ & $\mathrm{~T}_{1}$ & $\mathrm{~T}_{2}$ & \\
\cline { 2 - 4 } Mikoriza & & & & \\
M $_{0}$ & 39,60 & 26,73 & 21,42 & 29,25 \\
$\mathrm{M}_{1}$ & 40,62 & 24,12 & 25,37 & 30,03 \\
$\mathrm{M}_{2}$ & 35,87 & 25,72 & 23,45 & 28,34 \\
$\mathrm{M}_{3}$ & 36,15 & 23,90 & 22,03 & 27,36 \\
\hline Rataan & $38,06 \mathrm{a}$ & $25,12 \mathrm{~b}$ & $23,07 \mathrm{~b}$ & \\
\hline
\end{tabular}

Keterangan: Angka-angka yang diikuti oleh huruf yang berbeda menunjukkan pengaruh yang berbeda nyata antar perlakuan menurut DMRT pada taraf $\alpha=5 \%$. T0: top soil; T1: top soil + kompos kotoran kambing (1:1); T2: top soil + kompos kotoran kambing (1:2); M0: 0 g/tan mikoriza; M1: $10 \mathrm{~g} / \tan$ mikoriza; M2: $20 \mathrm{~g} / \tan$ mikoriza; M3: 30 g/tan mikoriza

Tabel 1 menunjukkan bahwa rataan tinggi bibit pada perlakuan kontrol $\left(\mathrm{T}_{0}\right)(38,06 \mathrm{~cm})$ berbeda nyata dengan perlakuan media tanam campuran kompos kotoran kambing ( $T_{1}$ dan $T_{2}$ ) yaitu $25,12 \mathrm{~cm}$ dan $23,07 \mathrm{~cm}$. Hal ini disebabkan karena mikoriza yang terkandung dalam media tanam top soil mengeluarkan enzim fosfatase. Menurut Lambers et al., (1998) enzim fosfatase yang dikeluarkan akibat aktivitas mikoriza mampu melepaskan $P$ yang terfiksasi oleh ion $\mathrm{Al}$ dan $\mathrm{Fe}$ sehingga $P$ tanah meningkat. Unsur $P$ sangat berperan dalam merangsang perkembangan akar. Luasnya area sebaran akar meningkatkan kapasitas penyerapan hara, hal ini juga mempengaruhi pertumbuhan vegetatif lainnya, seperti tinggi tanaman. Mosse (1981) menyatakan bahwa tanaman bermikoriza dapat menyerap $P$ dalam jumlah beberapa kali lebih banyak daripada tanaman tanpa mikoriza.

Pada penelitian ini menggunakan berbagai media tanam seperti top soil dan campuran top soil dengan kompos kotoran kambing. Menurut Einert (1972) media pertumbuhan yang cocok memainkan empat fungsi penting yaitu melayani sebagai reservoir untuk nutrisi tanaman, memasok air yang tersedia untuk tanaman, menyediakan gas untuk meningkatkan aerasi, yang memungkinkan akar untuk bernafas dan mempertahankan cukup air yang tersedia bersamasama dan bertindak sebagai tanaman. mendukung penjangkaran bagi akar tanaman. Pemberian berbagai jenis media tanam dan mikoriza belum mampu meningkatkan tinggi tanaman kakao. Menurut Suhardi (1989), kolonisasi akar oleh FMA akan maksimal pada tanah yang kondisinya kurang subur, dan lebih banyak terdapat pada akar-akar yang mengalami kekeringan daripada tempat yang terlalu banyak air. Pemberian pupuk dan mikoriza diharapkan dapat meningkatkan pertumbuhan bibit kakao. Fungi mikoriza arbuskular tidak mampu meningkatkan pertumbuhan bibit kakao, melainkan hanya meningkatkan persen infeksi akar oleh mikoriza saja (Rahmayanti et al., 2013). Pengaruh bahan organik yang diterapkan pada tanah tanaman mungkin 
tidak terlihat. Namun, kehadirannya secara positif mempengaruhi sifat-sifat tanah langsung, dan pelepasan nutrisi secara bertahap ke dalam tanah. Pelepasan bertahap nutrisi yang melekat dalam pupuk organik dapat bertanggung jawab atas peningkatan hasil panen dari plot tersebut di tahun-tahun berikutnya (Sumner, 1999).

\section{Volume Akar}

Berdasarkan hasil analisis sidik ragam, perlakuan media tanam dan interaksi pemberian mikoriza dengan media tanam berpengaruh nyata terhadap volume akar, sedangkan perlakuan pemberian mikoriza berpengaruh tidak nyata terhadap volume akar kakao (Tabel 2).

Tabel 2. Volume akar kakao melalui inokulasi mikoriza pada media tanam campuran kompos kotoran kambing

\begin{tabular}{ccccc}
\hline \multirow{2}{*}{ Perlakuan } & \multicolumn{4}{c}{ Redia Tanam } \\
\cline { 2 - 4 } Mikoriza & $\mathrm{T}_{0}$ & $\mathrm{~T}_{1}$ & $\mathrm{~T}_{2}$ & \\
$\mathrm{M}_{0}$ & $4,67 \mathrm{~b}$ & $1,47 \mathrm{ef}$ & $0,53 \mathrm{~h}$ & 2,22 \\
$\mathrm{M}_{1}$ & $5,67 \mathrm{a}$ & $1,07 \mathrm{fg}$ & $1,50 \mathrm{ef}$ & 2,74 \\
$\mathrm{M}_{2}$ & $4,23 \mathrm{c}$ & $0,93 \mathrm{gh}$ & $1,37 \mathrm{efg}$ & 2,18 \\
$\mathrm{M}_{3}$ & $3,00 \mathrm{~d}$ & $1,67 \mathrm{e}$ & $1,17 \mathrm{fg}$ & 1,94 \\
\hline Rataan & $4,39 \mathrm{a}$ & $1,28 \mathrm{~b}$ & $1,14 \mathrm{~b}$ &
\end{tabular}

Keterangan: Angka-angka yang diikuti oleh huruf yang berbeda menunjukkan pengaruh yang berbeda nyata antar perlakuan menurut DMRT pada taraf $\alpha=5 \%$. T0: top soil; T1: top soil + kompos kotoran kambing (1:1); T2: top soil + kompos kotoran kambing (1:2); M0: 0 g/tan mikoriza; M1: 10 g/tan mikoriza; M2: 20 g/tan mikoriza; M3: 30 g/tan mikoriza

Hasil uji lanjut pada Tabel 2 menunjukkan perlakuan kontrol $\left(T_{0}\right)$ ternyata meningkatkan volume akar $(4,39$ $\mathrm{cm}^{3}$ ) dan berbeda nyata dengan perlakuan pemberian kompos kotoran kambing ( $T_{1}$ dan $T_{2}$ ) yaitu $1,28 \mathrm{~cm}^{3}$ dan $1,14 \mathrm{~cm}^{3}$. Hal ini disebabkan karena mikoriza dapat berperan optimal pada tanah dengan kondisi kekeringan, berbeda dengan tanah berbahan organik tinggi yang mampu mengikat air. Sasli (2004) menyatakan bahwa pemberian mikoriza dapat meningkatkan laju pertumbuhan bibit kakao, efisiensi penggunaan air, dan ketahanan tanaman terhadap kekeringan. Anas (1997) menambahkan bahwa aktivitas mikoriza lebih tinggi pada tanah dengan kesuburan yang rendah. Tingginya aktivitas mikoriza menyebabkan sebaran akar semakin luas hal ini tentu berbanding lurus terhadap tingginya volume akar.

Hasil penelitian menunjukkan bahwa pemberian mikoriza $10 \mathrm{~g} / \mathrm{tan}$ pada media tanam top soil $\left(\mathrm{M}_{1} \mathrm{~T}_{0}\right)$ menghasilkan volume akar tertinggi $\left(5,67 \mathrm{~cm}^{3}\right)$ dan berbeda nyata dengan perlakuan lainnya (Tabel 2). Hal ini disebabkan karena infeksi mikoriza pada media tanam top soil dipengaruhi oleh faktor kondisi lingkungan yang beragam, seperti suhu, kelembaban tanah, kandungan fosfor dan nitrogen, serta $\mathrm{pH}$ tanah. Kepadatan spora berkolerasi positif terhadap peningkatan kolonisasi pada akar. Menurut Delvian (2007), pH tanah berpengaruh terhadap aktivitas enzim mikoriza, sehingga dengan terpengaruhnya enzim akan menyebabkan pertumbuhan tanaman menjadi lebih baik atau lebih buruk.

\section{Derajat Infeksi Akar}

Hasil analisis derajat infeksi akar oleh CMA pada akar tanaman kakao dapat dilihat pada Tabel 3. Bibit yang ditanam pada media tanam top soil dengan pemberian mikoriza $20 \mathrm{~g} / \tan$ menghasilkan derajat infeksi tertinggi $(80 \%)$ dan terendah pada media tanam campuran top soil dengan kompos kotoran kambing (1:2) tanpa pemberian mikoriza sebesar $0 \%$ (Tabel 3).

Tabel 3 menunjukkan bahwa pemberian mikoriza memberikan respon yang berbeda terhadap derajat infeksi akar. Pemberian mikoriza dengan berbagai konsentrasi (10 g/tan, $20 \mathrm{~g} / \mathrm{tan}$, dan $30 \mathrm{~g} / \mathrm{tan})$ pada media tanam top soil memberikan persentase tertinggi dibandingkan dengan pemberian mikoriza pada media tanam campuran kompos kotoran kambing. Hal ini disebabkan karena kondisi lingkungan dapat mempengaruhi populasi dan keanekaragaman mikoriza. Menurut Tamin et al., (2012) setiap ekosistem mempunyai kemungkinan dapat mengandung mikoriza dengan jenis yang sama atau berbeda karena keanekaragaman dan penyebarannya sangat bervariasi disebabkan oleh lingkungan yang bervariasi juga. Anas (1997) mengemukakan bahwa aktivitas mikoriza lebih tinggi pada tanah dengan kesuburan yang rendah. Pada kondisi tanah yang kering, tanah akan merangsang perkembangan spora dan terbentuknya kolonisasi dengan tanaman inang (Delvian, 2006).

Tabel 3. Hasil analisis derajat infeksi akar oleh CMA

\begin{tabular}{cc}
\hline Perlakuan & Persentase Infeksi Akar (\%) \\
\hline $\mathrm{M}_{0} \mathrm{~T}_{0}$ & 10 \\
$\mathrm{M}_{0} \mathrm{~T}_{1}$ & 5 \\
$\mathrm{M}_{0} \mathrm{~T}_{2}$ & 0 \\
$\mathrm{M}_{1} \mathrm{~T}_{0}$ & 60 \\
$\mathrm{M}_{1} \mathrm{~T}_{1}$ & 50 \\
$\mathrm{M}_{1} \mathrm{~T}_{2}$ & 50 \\
$\mathrm{M}_{2} \mathrm{~T}_{0}$ & 80 \\
$\mathrm{M}_{2} \mathrm{~T}_{1}$ & 70 \\
$\mathrm{M}_{2} \mathrm{~T}_{2}$ & 60 \\
$\mathrm{M}_{3} \mathrm{~T}_{0}$ & 70 \\
$\mathrm{M}_{3} \mathrm{~T}_{1}$ & 70 \\
$\mathrm{M}_{3} \mathrm{~T}_{2}$ & 60 \\
\hline
\end{tabular}

Keterangan: T0: top soil; T1: top soil + kompos kotoran kambing (1:1); T2: top soil + kompos kotoran kambing (1:2); M0: 0 g/tan mikoriza; M1: $10 \mathrm{~g} /$ tan mikoriza; M2: $20 \mathrm{~g} /$ tan mikoriza; M3: $30 \mathrm{~g} /$ tan mikoriza

Aplikasi mikoriza mendukung pertumbuhan dan kesehatan bibit kakao (Gambar 1a). Sesuai Putro (2013) bahwa bibit kakao berumur 5 bulan yang diinokulasi pupuk hayati mikoriza memiliki pertumbuhan lebih baik daripada yang tidak diinokulasi (kontrol). Persentase infeksi akar kakao yang diinokulasi pupuk hayati mikoriza lebih tinggi daripada perlakuan kontrol. Sementara tingkat infeksi akar bibit kakao umur 8 bulan yang diinokulasi pupuk hayati mikoriza lebih tinggi daripada infeksi akar tanaman kakao yang tidak diinokulasi pupuk hayati mikoriza.

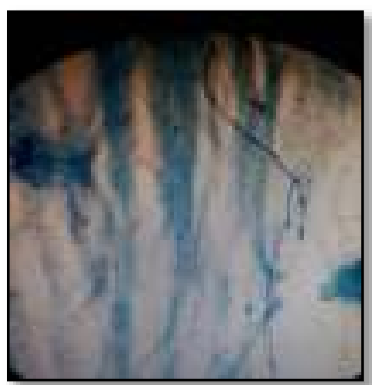

(aj)

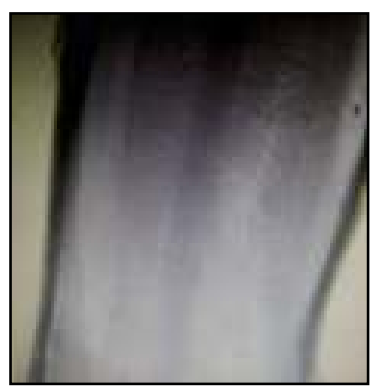

(b)
Gambar 1. Penampang akar (a) terinfeksi mikoriza, (b) tidak terinfeksi mikoriza 
Pada perlakuan tanpa mikoriza juga terlihat adanya infeksi akar (Gambar 1b), hal ini dikarenakan infeksi yang terjadi pada tanaman yang tidak diberi mikoriza merupakan infeksi dari mikoriza indigenous. Menurut Sundari et al., (2011) mikoriza indigenous merupakan jenis mikoriza yang ditemukan berasosiasi dengan perakaran tumbuhan secara alami tanpa campur tangan manusia dalam proses infeksi awal antara mikoriza dengan tumbuhan inang. Mikoriza indigenous memiliki potensi yang tinggi untuk membentuk infeksi yang ekstensif karena mengenali tanaman inangnya, selain itu mikoriza indigenous juga memiliki sifat toleransi yang lebih tinggi terhadap kondisi lingkungan dengan cekaman yang tinggi. Tanpa aplikasi mikoriza, derajat infeksi akar berkisar antara 0-10\%.

\section{KESIMPULAN}

Perlakuan media tanam berpengaruh nyata terhadap tinggi dan volume akar tanaman kakao. Media tanam Top soil menghasilkan rataan bibit tertinggi $(38,06 \mathrm{~cm})$ dan volume akar tertinggi $\left(4,39 \mathrm{~cm}^{3}\right)$. Interaksi pemberian mikoriza dengan media tanam berpengaruh nyata terhadap volume akar dengan perlakuan terbaik pada media tanam top soil yang diinokulasikan mikoriza $10 \mathrm{~g} / \tan \left(5,67 \mathrm{~cm}^{3}\right)$. Hasil analisis derajat infeksi akar oleh CMA menghasilkan infeksi tertinggi pada perlakuan media tanam top soil yang diinokulasikan mikoriza 20 g/tan (80\%).

\section{UCAPAN TERIMA KASIH}

Penulis mengucapkan terima kasih kepada Kementerian Riset dan Tekhnologi/Badan Riset dan Inovasi Nasional atas Dana Hibah Penelitian 2020 dengan Nomor Kontrak: 181/LLI/PG/2021 sehingga penelitian ini dapat berjalan lancar dan tepat waktu.

\section{DAFTAR PUSTAKA}

Anas, I. (1997). Bioteknogi Tanah. Laboratorium Tanah. Jurusan Tanah, Fakultas Pertanian IPB.

Arsyad, M., B. M. Sinaga \& S. Yusuf. (2011). Analisis Dampak Kebijakan Pajak Ekspor dan Subsidi Harga Pupuk terhadap Produksi dan Ekspor Kakao Indonesia Pasca Putaran Uruguay. Jurnal Sosial Ekonomi Pertanian, 8(1): 63-71.

Cahaya, A. T. \& Nugroho, D. A. (2009). Pembuatan Kompos dengan Menggunakan Limbah Padat Organik (Sampah Sayuran dan Ampas Tebu). Semarang: Teknik Kimia Universitas Diponegoro.

Dalimunthe, R. R., Irsal \& Meiriani. (2015). Respons Pertumbuhan Bibit Kakao (Theobroma cacao L.) terhadap Pemberian Pupuk Organik Vermikompos dan Interval Waktu Penyiraman Air pada Tanah Subsoil. Jurnal Agroekoteknologi, 3(1): 188-197.

Delvian. (2006). Keanekaragaman dan Potensi Pemanfaatan Cendawa Mikoriza Arbuskula (CMA) di Hutan Pantai. Disertasi Program Pascasarjana Institut Pertanian Bogor.

Delvian. (2007). Pengaruh Spesies Inang dan Sumber Nutrisi Terhadap Pertumbuhan Spora Fungi Mikoriza Arbuskula. J. Natur Indonesia, 10(2): 70-72.

Einert, A. E. (1972). Performance of rice hull media for pot Easter lilies under three forcing systems. HortScience.
Hartatik, W. \& Widowati. (2006). Pupuk Kandang, Pupuk Organik, dan Pupuk Hayati. Bogor: Balai Besar Penelitian dan Pengembangan Sumber Daya Lahan Pertanian.

Islami, Titiek, Utomo \& Wani, H. (1995). Hubungan Tanah, Air, dan Tanaman. Semarang: IKIP Semarang Press.

Lambers, H., F. S. Chapin, \& T. L. Pons. (1998). Plant Fisiological Ecalogical. New York: Springer-Verlag.

Mosse, B. (1981). Vesicular-Arbuscular Mycorrhiza Research for Tropical Agric. Research Buletin. HI of Tropical Agriculture and Human Resources. New Phytol. Manila.

Noertjahyani (2012). Respon Pertumbuhan Kolonisasi Mikoriza dan Hasil Tanaman Kedelai sebagai Akibat dari Takaran Kompos dan Mikoriza Arbuskular. Sumedang: Fakultas Pertanian Universitas Winaya Mukti.

Noli, Z. A., W. S. Netty \& E. M. Sari. (2011). Eksplorasi Cendawan Mikoriza Arbuskula (CMA) Indigenous yang Berasosiasi dengan Begonia resecta di Hutan Pendidikan dan Penelitian Biologi (HPPB). Prosiding Seminar Nasional Biologi: Meningkatkan Peran Biologi dalam Mewujudkan National Achievment with Global Reach. Departemen Biologi FMIPA Universitas Sumatera Utara, Medan. hlm. 538-539.

Putro, I. S. (2013). Pengaruh Pupuk Hayati Mikoriza Terhadap Pertumbuhan dan Kesehatan Bibit Kakao (Doctoral dissertation, Universitas Gadjah Mada).

Rahmayanti, A. Y., Rini, M. V., Arif, M. S. \& Yusnaini, S. (2013). Pengaruh pemberian fungi mikoriza arbuskular dan kompos kulit buah kakao pada pertumbuhan bibit kakao (Theobroma cacao L.). Jurnal Agrotek Tropika, 1(2).

Rungkat, J. A. (2009). Peranan MVA dalam Meningkatkan Pertumbuhan dan Produksi Tanaman. Jurnal FORMAS, 4: 270-276.

Sasli, I. (2004). Peranan Mikoriza Vesikula Arbuskula (MVA) dalam Peningkatan Resistensi Tanaman terhadap Cekaman Kekeringan. Makalah Pribadi Pengantar ke Falsafah Sains (PPS702). Sekolah Pasca Sarjana/ S3. Institut Pertanian Bogor.

Setiadi, Y. (1989). Pemanfaatan Mikroorganisme dalam Kehutanan. PAU Bioteknologi IPB-Lembaga Sumberdaya Informasi IPB. Bogor. 103 hal.

Sub Direktorat Statistik Tanaman Perkebunan. (2020). Statistik Kakao Indonesia 2019. Jakarta: Badan Pusat Statistik.

Suhardi. (1989). Mikoriza Vesikular Arbuskular (MVA). Pusat Antar Universitas (PAU) Bioteknologi UGM. Yogyakarta. $128 \mathrm{hlm}$.

Sulistyowati, E. (2014). Effectiveness of Sex Pheromone in Controlling Cocoa Pod Borer, Conopomorpha cramerella (Snell). Pelita Perkebunan, 30(2): 115122.

Sumner, M. E. (Ed.). (1999). Handbook of soil science. CRC press.

Sundari, S., Tutik H., \& Indah T. (2011). Isolasi dan Identifikasi Mikoriza Indigenous dari Perakatan Tembakau Sawah di Area Persawahan Kabupaten 
Pamekasan Madura. Surabaya: Jurusan Biologi, Fakultas Matematik dan IImu Pengetahuan Alam, Institut Sepuluh November.

Tamin, R. P., Nursanti, \& Albayudi. (2012). Indentifikasi Jenis dan Perbanyakan Endomikoriza Lokal di Hutan Kampus Universitas Jambi. J. Penelitian Universitas Jambi Seri SAINS, 14(1): 23-28.

Wicaksono, M. I., M. Rahayu, \& Samanhudi. (2014). Pengaruh Pemberian Mikoriza dan Pupuk Organik Terhadap Pertumbuhan Bawang Putih. Jurnal IImu Pertanian, 29(1). 